\title{
Miskonsepsi Kimia, Sebuah Misteri
}

\author{
Suyono $^{1}$ \\ 1. Prodi Pendidikan Kimia FMIPA Unesa
}

\begin{abstract}
Abstrak - Kajian ini bertujuan untuk membuka tabir misteri pada miskonsepsi kimia. Pintu pembuka tabir itu minimal berupa kerangka berpikir yang mengarah kepada jawaban awal terhadap pertanyaan kenapa remediasi miskonsepsi kimia masih menyisakan sejumlah individu resisten. Metaanalisis telah dilakukan terhadap berbagai hasil penelitian tentang remediasi miskonsepsi kimia. Dari 11 artikel Conceptual Change Text (CCT) yang dianalisis terdapat 6 (enam) artikel yang pada akhir proses pengubahan konsepsi masih menyisakan lebih dari $20 \%$ individu miskonsepsi atau masih didapatinya miskonsepsi kimia pada setiap individu lebih dari 20\% konsep yang diujikan. Enam artikel itu dipublikasikan antara lain oleh: (1) Ultay et al. (2014), (2) Pabuccu and Geban (2012), (3) Balci (2006), (4) Pinarbasi et al. (2006), (5) Gunay (2005), dan (6) Calik et al. (2005). Upaya yang dilakukan untuk meremediasi individu miskonsepsi pada sejumlah konsep kimia belum ada yang berhasil menghilangkan keseluruhan miskonsepsi pada individu. Proses akomodasi adalah inti dari proses pengubahan konsepsi individu. Oleh karena itu, terhadap dokumen CCT yang terlampir pada keenam artikel di atas dianalisis keberadaan cara-cara penciptaan empat kondisi untuk terjadinya proses akomodasi. Empat kondisi itu adalah: (1) harus ada ketidakpuasan terhadap konsepsi yang telah ada, (2) sebuah konsepsi baru yang dihadirkan harus dapat dimengerti atau jelas, (3) konsepsi baru yang dihadirkan harus masuk akal, dan (4) konsepsi baru menampakkan potensi atau peluang dapat dimanfaatkan untuk pengembangan lebih lanjut. Dari enam dokumen CCT yang dianalisis didapati lima dokumen CCT yang diimplementasikan oleh Ultay et al. (2014), Balci (2006), Pinarbasi et al. (2006), Gunay (2005), dan Calik et al. (2005) tidak memfasilitasi pengkondisian akomodasi yang keempat. Apakah tidak dipenuhinya kondisi akomodasi yang keempat berkorelasi dengan $20 \%$ individu yang masih tetap miskonsepsi, adalah sebuah misteri yang perlu dipecahkan. Jika asumsi tentang korelasi itu benar, maka kerangka berpikir yang mengarah kepada jawaban awal terhadap pertanyaan kenapa remediasi miskonsepsi kimia masih menyisakan sejumlah individu resisten miskonsepsi adalah pemberian perhatian kepada pengkondisian proses akomodasi nomor empat. Jika ditinjau dari tiga pertanyaan keilmuan, maka pemahaman atas kemanfaatan sebuah konsep tergolong ke dalam pertanyaan aksiologi. Miskonsepsi kimia, sebuah misteri yang menarik untuk diketahui dengan pasti penyebab dan solusinya. Ruang riset kearah ini masih terbuka lebar. Apakah pelibatan individu kepada kajian aksiologi dapat membantu tahap ekuilibrasi dan rekonstruksi konsepsi individu, masih juga misteri yang perlu dijawab melalui riset yang komprehensif.
\end{abstract}

Kata kunci: miskonsepsi, conceptual change text, akomodasi

\section{PENDAHULUAN}

Miskonsepsi adalah ketidaksesuaian pemahaman konsep siswa dengan pengertian ilmiah yang dirumuskan oleh ilmuwan di bidangnya (Chi, 2017; Taş et al. 2015; Ibrahim, 2012; Dhindsa \& Treagust, 2009; Unal, Costu \& Ayas, 2010). Miskonsepsi menjadi hambatan yang sangat besar dalam pembelajaran yang lebih bermakna (Pabuccu \& Geban, 2012). Oleh sebab itu, jumlah individu yang mengalami miskonsepsi harus dikurangi. Beban miskonsepsi yang dipikul setiap individu harus direduksi. Upaya reduksi miskonsepsi kimia pada individu dapat dilakukan melalui pembelajaran remediasi menggunakan strategi conceptual change (Pabuccu \& Geban, 2006). Strategi conceptual change terbukti efektif mengurangi miskonsepsi kimia pada invidu (Ultay et al., 2014; Sinatra and Broughton, 2011; Ozdemir and Clark, 2007; Baser; Zirbel, 2004). Sejauh

${ }^{1}$ Corresponding author: Prodi Pendidikan Kimia FMIPA Unesa, Email: suyono@unesa.ac.id 
mana efektifitas strategi conceptual change masih perlu dikaji lebih lanjut. Sebelum dilakukan kajian lebih lanjut perlu dipahami terlebih dahulu tentang strategi ini.

Strategi conceptual change adalah strategi pembelajaran yang bertujuan mengubah konsepsi individu dan membentuk konsepsi baru yang lebih bermakna, merubah konsepsi individu yang salah (miskonsepsi) menjadi tidak miskonsepsi lagi (Pabuccu \& Geban, 2006). Strategi conceptual change mendasarkan kepada ide-ide Piaget dan konstruktivisme (Baser, 2006). Menurut Baser, strategi ini mendorong terciptanya ketidakpuasan dalam benak individu terhadap konsepsinya, terjadi konflik kognitif. Ketika terjadi ketidakpuasan seperti itu akan terjadi re-adaptasi pada individu untuk kembali mencapai keseimbangan (ekuilibrasi) (Piaget, 2005). Dengan kalimat sederhana, inti dari strategi conceptual change adalah seperti berikut ini. Konsepsi salah yang terbangun di dalam struktur kognitif (skemata) individu, didisekuilibrasi terlebih dahulu untuk selanjutnya ditata kembali, selanjutnya diekuilibrasi menjadi konsepsi yang benar.

Inti conceptual change menurut Posner et al. (1982) adalah proses akomodasi. Akomodasi adalah salah satu varian dari konsep adaptasi yang dikembangkan oleh Piaget (Suyono \& Hariyanto, 2015). Akomodasi kognitif dipahami sebagai proses pengubahan struktur kognitif (skema) yang sudah dimiliki individu sebelumnya untuk disesuaikan dengan objek stimulus eksternal. Proses pengubahan ini dapat berlangsung jika terjadi konflik kognitif (desonansi kognitif) pada benak individu. Penciptaan konflik kognitif dapat dilakukan dengan menunjukkan anomali (Read, 2004), menghadapkan individu pada informasi yang bertolak belakang dengan konsepsi yang telah dimiliki (Chi, 2008), pemberian contoh-contoh tandingan, demonstrasi, dan eksperimen. Jika desonansi kognitif yang terjadi diikuti kondisi disequilibrium (ketidakseimbangan) skema, perombakan dan penataan kembali skema yang menolak konsepsi lama, maka secara otomatis individu akan memiliki kemauan untuk mengakomodasi konsep baru yang benar (Read, 2004).

Demikian pentingnya proses akomodasi dalam proses pengubahan konsepsi individu, sampaisampai Posner, Strike, Hewson and Gertzog di tahun 1982 mengkaji dan menuliskan empat kondisi penting yang harus dipenuhi agar terjadi akomodasi. Empat kondisi itu adalah: (1) harus ada ketidakpuasan terhadap konsepsi yang telah ada, (2) sebuah konsepsi baru yang dihadirkan harus dapat dimengerti atau jelas, (3) konsepsi baru yang dihadirkan harus masuk akal, dan (4) konsepsi baru menampakkan potensi atau peluang dapat dimanfaatkan untuk pengembangan lebih lanjut seperti membuka jalan baru bagi penelitian/inkuiri. Artikel yang ditulis Posner et al. (1982) walau tergolong terbitan lama, namun banyak menginspirasi peneliti-peneliti berikutnya bahkan hingga saat ini masih cukup banyak yang mensitasi ketika mengkaji atau melakukan penelitian terkait dengan conceptual change.

Sebagaimana disebutkan pada bagian akhir paragraf pertama artikel ini, perlu dilakukan analisis lebih lanjut tentang efektifitas strategi conceptual change pada pembelajaran kimia. Kajian ini bertujuan untuk membuka tabir misteri pada miskonsepsi kimia. Pintu pembuka tabir itu minimal berupa kerangka berpikir yang mengarah kepada jawaban awal terhadap pertanyaan kenapa remediasi miskonsepsi kimia masih menyisakan sejumlah individu resisten. Peneliti melakukan analisis keberhasilan implementasi strategi conceptual change pada pembelajaran kimia, khususnya yang memiliki kata kunci (keyword) conceptual change text untuk menjawab pertanyaan kenapa remediasi miskonsepsi kimia masih menyisakan sejumlah individu yang masih bertahan miskonsepsi.

\section{METODE}

Metaanalisis dilakukan terhadap berbagai hasil penelitian tentang remediasi miskonsepsi kimia. Telah didapatkan 11 artikel Conceptual Change Text (CCT) baik dalam bentuk modul, worksheet, maupun bentuk-bentuk teks yang lain yang selanjutnya dianalisis dalam 2 (dua) tahap. Tahap pertama, untuk menetapkan artikel yang pada akhir proses pengubahan konsepsi masih menyisakan lebih dari $20 \%$ individu miskonsepsi atau masih didapatinya miskonsepsi kimia pada 
setiap individu lebih dari 20\% konsep yang diujikan. Tahap kedua, analisis diarahkan kepada content di dalam teks hasil penetapan pada tahap pertama, apakah telah memenuhi empat kondisi yang dituntut agar terjadi akomodasi pada struktur kognitif pengguna teks. Pemenuhan empat kondisi itu dilihat baik dari sisi konsistensi (konstruk) maupun relevansi (isi).

\section{HASIL DAN PEMBAHASAN}

Deskripsi hasil metaanalisis kegagalan implementasi strategi conceptual change dari sejumlah artikel ilmiah dinarasikan seperti berikut ini. Term kegagalan dimaknai ditemukannya sejumlah siswa/mahasiswa yang masih miskonsepsi atau masih didapatinya miskonsepsi kimia pada setiap siswa/mahasiswa setelah pembelajaran menggunakan conceptual change text (CCT). Penggunaan CCT pada konsep kesetimbangan kimia telah dicoba oleh Özmen and Naseriazar (2017) dan berhasil menurunkan rerata persentase miskonsepsi yang dimiliki oleh mahasiswa (di Turki) dari 54\% menjadi 30\%. Artinya, implementasi CCT kesetimbangan kimia ini masih menyisakan rerata miskonsepsi pada mahasiswa sebesar 30\%, masih gagal menghilangkan keseluruhan miskonsepsi yang dimiliki mahasiswa. Penggunaan CCT yang ditujukan untuk menurunkan miskonsepsi siswa SMA pada konsep elektrokimia juga belum berhasil (masih gagal) menurunkan miskonsepsi siswa, meskipun ada kenaikan rata-rata skor tes awal $\left(\mathrm{x}^{-}=6,21\right)$ menjadi $\mathrm{x}^{-}=15,08$ pada tes akhir (Önder, 2017). Amponsah and Ochonogor (2016) melakukan hal sama sebagaimana yang dilakukan Önder. Keduanya menggunakan CCT konsep elektrokimia pada kelompok siswa perempuan dan laki-laki. Simpulan penelitiannya, bahwa CCT yang digunakan tidak bias gender, tidak menunjukkan perbedaan dampak yang signifikan akibat perbedaan jenis kelamin. Kegagalan menghilangkan keseluruhan miskonsepsi yang ada pada diri siswa masih dialami oleh Amponsah and Ochonogor, persentase rata-rata miskonsepsi pada kedua kelas (perempuan dan laki-laki) masih 43,6\%. Ültay et al. (2014) memadukan (CCT) dengan strategi REACT (Relating, Experiencing, Applying, Cooperating and Transferring) untuk menurunkan miskonsepsi mahasiswa pada konsep kimia larutan. Penggunaan CCT dengan model analogi untuk memperbaiki miskonsepsi siswa pada konsep ikatan kimia masih juga menyisakan 23,5\% siswa miskonsepsi (Pabuçcu \& Geban, 2012). Çetingül and Geban (2011) menguji dampak CCT dengan analogi pada konsep yang lain, yaitu asam basa dan menemukan rerata persentase miskonsepsi pada siswa sebesar 41,34\%. Çostu et al. (2009) menggunakan strategi conceptual change untuk memperbaiki miskonsepsi mahasiswa (di Turki) pada konsep kimia penguapan dan menemukan siswa miskonsepsi pada tes akhir sebesar 6,38\%. Pembelajaran konsep kimia asam basa dengan menggunakan CCT masih menyisakan miskonsepsi siswa sebesar 8,35\% (Demircioğlu, 2009), pada konsep reaksi kimia menyisakan miskonsepsi sebesar 19,6\% (Taştan et al., 2008), pada konsep laju reaksi menyisakan miskonsepsi sebesar 35,8\% (Balci, 2006) dan pada konsep atom dan molekul masih menyisakan miskonsepsi sebesar 55\% (Günay, 2005). Temuan lain yaitu pembelajaran CCT pada konsep ikatan kimia dengan analogi masih menyisakan miskonsepsi siswa sebesar 64,7\% (Pabuçcu \& Geban, 2006). Artinya, penggunaan CCT dengan analogi belum berhasil menghilangkan totalitas persentase miskonsepsi yang dimiliki oleh siswa. Penggunaan CCT dalam bentuk worksheet berbasis konflik kognitif berhasil menurunkan persentase miskonsepsi asam basa yang dimiliki siswa dari 18-84\% menjadi 0-10\% (Demircioğlu et al., 2005).

Jika diperhatikan keseluruhan hasil penelitian sebagaimana dideskripsikan pada paragraf di atas dapat ditarik sebuah simpulan bahwa upaya-upaya yang dilakukan untuk meremediasi siswa/mahasiswa yang mengalami miskonsepsi pada sejumlah konsep kimia menggunakan CCT belum ada yang berhasil menghilangkan keseluruhan miskonsepsi pada siswa/mahasiswa. Masih ditemukannya individu-individu yang masih miskonsepsi atau masih didapatinya miskonsepsi kimia pada setiap individu dalam persentase yang cukup besar (di atas 20\%). Artinya, boleh dinyatakan bahwa terjadi kegagalan penggunaan CCT merubah konsepsi yang telah terbangun di dalam skema individu. Dari 11 artikel CCT yang peneliti kaji terdapat 6 (enam) artikel yang pada 
akhir proses pengubahan konsepsi masih menyisakan lebih dari 20\% individu yang masih miskonsepsi atau masih didapatinya miskonsepsi kimia pada setiap individu lebih dari 20\% konsep yang diujikan, antara lain: (1) Ultay et al. (2014), (2) Pabuccu and Geban (2012), (3) Balci (2006), (4) Pinarbasi et al. (2006), (5) Gunay (2005), dan (6) Calik et al. (2005).

Sebagaimana telah disebutkan sebelumnya bahwa akomodasi adalah inti dari proses pengubahan konsepsi individu. Kegagalan merubah konsepsi yang salah pada siswa/mahasiswa dapat dipastikan karena kegagalan proses akomodasi di dalam struktur kognitif (skema) siswa/mahasiswa. Kegagalan proses pengubahan konsepsi individu, jika didasarkan kepada pendapat Posner et al. boleh jadi karena tidak dipenuhi empat kondisi penting agar terjadi akomodasi. Untuk memastikan dugaan itu peneliti melakukan analisis pemenuhan atas empat kondisi penting untuk terjadinya proses akomodasi yang tersurat di dalam dokumen teks CCT yang digunakan oleh enam kelompok peneliti. Keenam kelompok peneliti ini mengimplementasikan pengkondisian untuk terjadinya proses akomodasi menggunakan CCT melalui cara-cara yang bervariasi. Cara-cara yang dilakukan peneliti untuk menciptakan ketidakpuasan terhadap konsepsi yang ada (kondisi 1) antara lain (a) menggunakan anomali, (b) menggunakan gambar, diagram, grafik, demonstrasi, dan penyajian animasi yang diperkirakan dapat menciptakan konflik kognitif, (c) menyediakan teks berisi ide berbeda dari dua siswa yang berbeda atas sebuah konsep yang sama, (d) menyediakan penjelasan ilmiah yang disertai contoh, dan (e) menyampaikan pernyataan mengakui suatu situasi atau kondisi anomali, suatu peminatan, kecemasan yang diperkirakan dapat menciptakan konflik kognitif. Keenam kelompok peneliti CCT itu mengkondisikan agar konsepsi baru dapat dimengerti oleh individu (kondisi 2) melalui cara-cara antara lain (a) menyediakan teks yang berisi dua gagasan dari siswa A dan B yang berbeda (terdapat konsepsi yang benar dan konsepsi yang salah), (b) menggunakan diagram atau gambar untuk merepresentasikan konsepsi yang dimiliki, (c) menyediakan analogi atau metafora untuk merepresentasikan konsepsi siswa/mahasiswa, (d) menggunakan linguistik atau bahasa dan simbolik untuk merepresentasikan konsepsi supaya dapat dimengerti, (e) menyediakan kegiatan eksperimen atau observasi, visualisasi gambar, video atau pemodelan, (f) menggunakan fenomena atau pemasalahan untuk dapat diselesaikan, dan (g) menggunakan contoh-contoh dalam kehidupan nyata supaya dapat merepresentasikan konsepsi siswa/mahasiswa agar dapat dimengerti.

Upaya yang dilakukan agar individu pengguna CCT dapat menerima konsep baru sebagai sesuatu yang masuk akal (kondisi 3) antara lain (a) memberikan alasan yang menunjukan konsistensi antara konsepsi ilmiah dan data hasil pengamatan, (b) menggunakan analogi atau metafora untuk merepresentasikan konsepsi yang baru supaya masuk akal, (c) menyediakan pemodelan atau contoh-contoh yang baru, (d) menyediakan visualisasi gambar-gambar atau video untuk memperkuat sebuah konsepsi yang baru, (e) memberikan alasan yang meliputi penjelasan hubungan kausalitas atau sebab akibat dari sebuah konsep, (f) memberikan bantuan untuk terjadinya ekuilibrasi, melalui pertanyaan-pertanyaan yang menuntut jawaban argumentatif yang mengandung konsepsi yang baru, (g) menyediakan teks yang dikembangkan dengan memuat tahapan rekonstruksi pemahaman individu, melalui pemberian pertanyaan kontekstual atau pertanyaan yang berkaitan dengan fenomena dalam kehidupan sehari-hari, yang menuntut jawaban siswa/mahasiswa berupa penjelasan yang mengandung sebuah konsepsi baru, dan (h) menyediakan teks yang telah dikembangkan dengan memuat tahapan rekonstruksi pemahaman individu melalui penugasan penyusunan tabel analisis konsep yang berhubungan dengan konsepsi yang baru.

Untuk meyakinkan individu bahwa konsep baru yang diperoleh akan memberikan manfaat (kondisi 4) dilakukan dengan cara-cara antara lain (a) menyediakan pemberian bantuan untuk terjadinya ekuilibrasi supaya konsepsi baru bermanfaat, (b) menyediakan fenomena baru supaya siswa/mahasiswa dapat mengimplementasikan konsep barunya, (c) menyediakan pertanyaan- 
pertanyaan untuk mengungkapkan konsepsi baru yang lebih bermanfaat, (d) memberikan penyataan-pernyataan sebagai bagian dari konsepsi yang mungkin akan dilakukan di masa depan.

Hasil analisis yang telah peneliti lakukan terhadap dokumen CCT yang dikembangkan pada enam artikel ditinjau atas dasar keberadaan cara-cara penciptaan empat kondisi akomodasi yang dipersyaratkan Posner ditunjukkan pada Gambar 1.

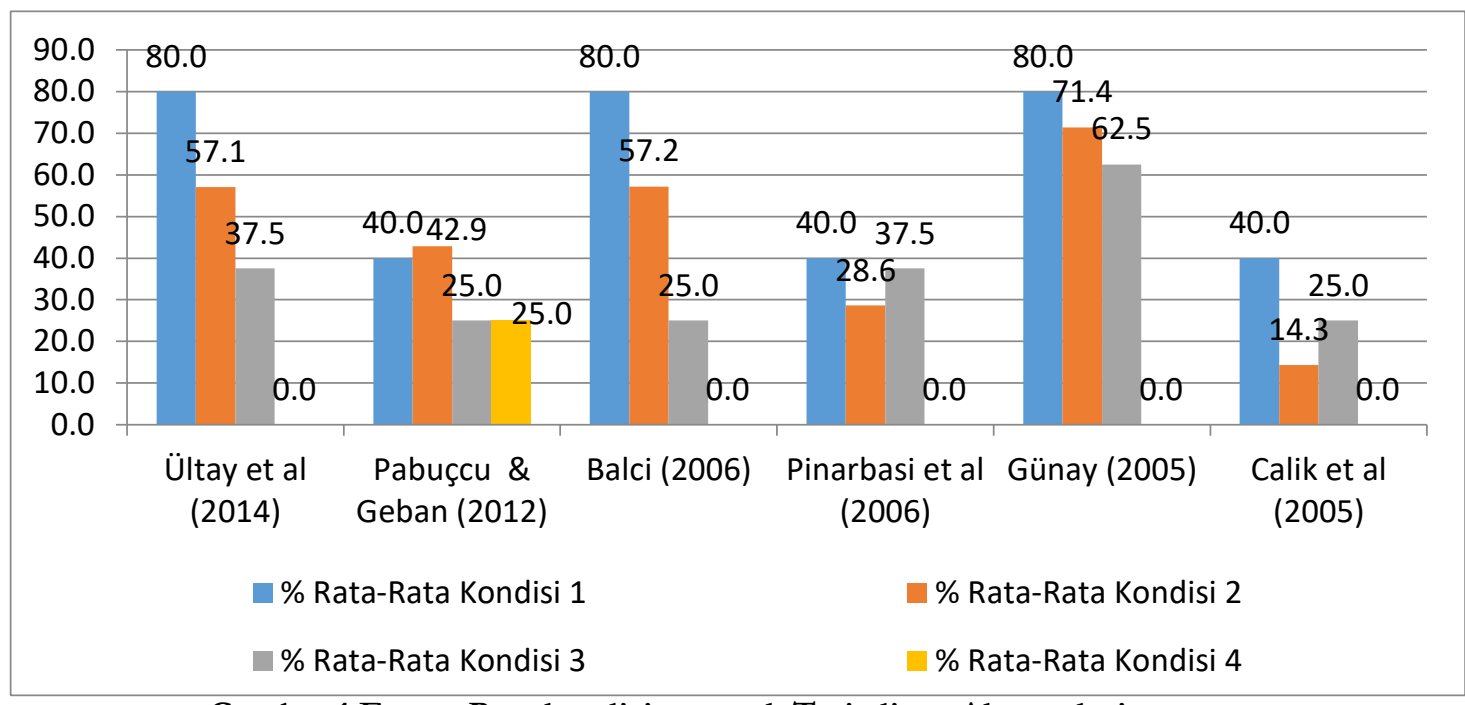

Gambar 1 Empat Pengkondisian untuk Terjadinya Akomodasi

Angka $80 \%$ pada histogram paling kiri dalam Gambar 1 merepresentasikan bahwa dalam pemenuhan kondisi 1 Ultay et al. (2014) memasukkan tiga cara dari empat cara yang sebenarnya dapat dilakukan (3/4 X 100\%). Demikian penjelasan yang berlaku bagi angka-angka pada histogram Gambar 1. Jika diperhatikan Gambar 1 maka, nampak bahwa CCT yang diimplementasikan oleh Ultay et al. (2014), Balci (2006), Pinarbasi et al. (2006), Gunay (2005), dan Calik et al. (2005) tidak memfasilitasi pengkondisian keempat "konsep baru yang diperoleh akan memberikan manfaat." Ketika pengkondisian keempat ini tidak dipenuhi, CCT menjadi tidak efektif dengan terbukti masih menyisakan persentase miskonsepsi siswa sebesar 20\%.

Apakah tidak dipenuhinya kondisi akomodasi yang keempat berkorelasi dengan $20 \%$ individu yang masih tetap miskonsepsi, adalah sebuah misteri yang perlu dipecahkan. Jika asumsi tentang korelasi itu benar, maka kerangka berpikir yang mengarah kepada jawaban awal terhadap pertanyaan kenapa remediasi miskonsepsi kimia masih menyisakan sejumlah individu resisten miskonsepsi adalah pemberian perhatian kepada pengkondisian proses akomodasi nomor empat.

Solusi yang ditawarkan adalah mengimplementasikan inovasi pembelajaran conceptual change dengan memberikan perhatian terhadap pengkondisian Posner nomor empat (sebuah konsepsi baru harus bermanfaat). Jika ditinjau dari tiga pertanyaan keilmuan, maka pemahaman atas kemanfaatan sebuah konsep tergolong ke dalam pertanyaan aksiologi. Aksiologi membahas pertanyaan-pertanyaan yang berkaitan dengan makna dan manfaat suatu pengetahuan (Suriasumantri, 2013). Jika tetap diimplementasikan conceptual change text dalam reduksi miskonsepsi kimia pada individu, maka masih perlu ditambahkan suplemen yang memfasilitasi individu untuk mendapat penguatan bahwa "konsep baru yang diperoleh akan memberikan manfaat." Suplemen itu dapat dirancang atau dikemas dalam bentuk worksheet yang memukau, yang menunjukkan betapa pentingnya memiliki konsepsi kimia yang kuat. Worksheet kimia yang memperkaya pemahaman kimia individu dari sisi aksiologi dan jika perlu dilengkapka dengan tampilan video yang merepresentasi aksiologi konsep kimia atau dikembangkan link ke web yang memiliki relevansi tinggi. 


\section{KESIMPULAN}

Simpulan, dari enam artikel CCT yang dianalisis didapati lima artikel CCT yang diimplementasikan oleh sejumlah penelitia tidak memfasilitasi pengkondisian akomodasi yang keempat. Apakah tidak dipenuhinya kondisi akomodasi yang keempat berkorelasi dengan 20\% individu yang masih tetap miskonsepsi, adalah sebuah misteri yang perlu dipecahkan. Rekomendasi, jika asumsi tentang korelasi itu benar, maka kerangka berpikir yang mengarah kepada jawaban awal terhadap pertanyaan kenapa remediasi miskonsepsi kimia masih menyisakan sejumlah individu resisten miskonsepsi adalah pemberian perhatian kepada pengkondisian proses akomodasi nomor empat. Jika ditinjau dari tiga pertanyaan keilmuan, maka pemahaman atas kemanfaatan sebuah konsep tergolong ke dalam pertanyaan aksiologi. Miskonsepsi kimia, sebuah misteri yang menarik untuk diketahui dengan pasti penyebab dan solusinya. Ruang riset kearah ini masih terbuka lebar. Apakah pelibatan individu kepada kajian aksiologi dapat membantu tahap ekuilibrasi dan rekonstruksi konsepsi individu, masih juga misteri yang perlu dijawab melalui riset yang komprehensif.

\section{DAFTAR RUJUKAN}

Amponsah, K. D. And Ochonogor, C. E. (2018). Facilitating Conceptual Change in Students' Comprehension of Electrochemistry Concepts through Collaborative Teaching Strategy. American Journal of Educational Research, 2018, Vol. 6, No. 6, 596-601. Science and Education Publishing DOI:10.12691/education-6-6-3.

Balci, C. (2006). Conceptual Change Text Oriented Instruction to Facilitate Conceptual Change in Rate of Reaction Concepts. A Thesis Submitted to the Graduate School of Natural and Applied Sciences of Middle East Technical University.

Calik, M., Alipas, A., \& Richard, K. C. (2005). Enhancing Pre-Service Elementary Teachers' Conceptual Understanding of Solution Chemistry with Conceptual Change Text. International Journal of Science and Mathematics Education 5: 1-28.

Çetingül, I. \& Geban, Ö. 2011. Using Conceptual Change Text with Analogies for Misconceptions in Acids and Bases. Journal of Education, 41, page 112-123.

Chi, M.T.H. 2008. Three Types of Conceptual Change: Belief Revision, Mental Model Transformation, and categorical Shift. In S. Vasniadou (Ed) Handbook of research on conceptual change. Hillsdale, $\mathrm{NJ}:$ Erlbaum.

Chi, M. T. H. (2017). Two Kinds and Four Sub Types of Misconceived Knowledge Ways to Change it and the Learning Outcomes. International Handbook of Research on Conceptual Change Routledge.

Demircioğlu, G. (2009). Comparison of the Effects of Conceptual Change Texts Implemented After and Before Instruction on Secondary School Students' Understanding of Acid Base Concepts. Journal AsiaPacific Forum on Science Learning and Teaching, Volume 10, Issue 2, Article 5, p.1.

Dhinsda, H. and Treagust, D. (2009). Conceptual Understanding of Bruneian Tertiary Students: Chemical Bonds and Structure. Brunei International Journal of Science and Mathematics Education. 1 (1), 3351.

Günay, B. (2005). Conceptual Change Text Oriented Instruction Facilitate Conceptual Change in Atoms and Molecules. A Thesis Submitted to the Graduate School of Natural and Applied Sciences of Middle East Technical University.

Ibrahim, M. (2012). Konsep, Miskonsepsi, dan Cara Pembelajarannya. Surabaya: Unesa Press.

Önder, I. 2017. The Effect of Conceptual Change Texts Supplemented Instruction on Students' Achievement in Electrochemistry. International Online Journal of Educational Sciences, 2017, 9 (4), $969-975$.

Ozdemir and Clark. 2007. An Overview of Conceptual Change Theories. Journal of Mathematics, Science and Technology Education. 3, (4), 351-361. 
Özmen, H. \& Naseriazar, A. (2017). Effect of Simulations Enhanced with Conceptual Change Texts on University Students' Understanding of Chemical Equilibrium. Journal Serb. Chem. Soc. 82 (0) 1-16, https://doi.org/10.2298/JSC161222065O.

Pabuçcu, A \& Geban, O. (2012). "Students' Conceptual Level of Understanding on Chemical Bonding”. H.U. Journal of Education Sciences. H.U. Eğitim Fakültesi Dergisi, 4 (3), 563-580.

Piaget, J. (2005). The Psychology of Intelligence. (M. Piercy, \& D. E. Berlyne, Trans.). London: Taylor \& Francis e-Library.

Pinarbasi, T., Canpolat, N., \& Bayrakc, S. (2006). An Investigation of Effectiveness of Conceptual Change Text-oriented Instruction on Students' Understanding of Solution Concepts. Research in Science Education (2006) 36: 313-335.

Posner, G. J., Strike, K. A., Hewson, P. W., \& Gertzog, W. A. (1982). Accomodation of a Scientific Conception : Toward a Theory of Conceptual Change. Journal Science of Education 66 (2): 211-227.

Read, J, R. 2004. Children's Misconceptions and Conceptual Change in Science Education. School of Chemistry The University of Sydney.

Sinatra, G. M., \& Suzanne, H. B. 2011. "Bridging Reading Comprehension and Conceptual Change in Science Education: The Promise of Refutation Text," International Reading Association, Reading Research Quarterly 46(4) pp. 374-393.

Suriasumantri, J.S. (2013). Filsafat Ilmu Sebuah Pengantar Populer. Jakarta: Sinar Harapan.

Suyono \& Hariyanto. (2015). Belajar dan Pembelajaran Teori dan Konsep Dasar. Bandung: PT Remaja Rosdakarya.

Taş, E., Gulen, S., Oner, Z., \& Ozyurek, C. (2015). The Effects of Classic and Web Designed Conceptual Change Text on the Subject of Water Chemistry. International Electronic Journal of Elementary Education: 7, 263.

Taştan, Ö., Yalçinkaya, E., \& Boz, Y. (2008). Effectiveness of Conceptual Change Text-oriented Instruction on Students' Understanding of Energy in Chemical Reactions. Journal Sci Education Technology, Volume 17, 444-453.

Ültay, N., Durukan, Ü. G., \& Ültay, E. (2014). Evaluation of the Effectiveness of Conceptual Change Texts in the REACT Strategy. Journal is The Royal Society of Chemistry.

Unal, S., Costu, B. \& Ayas, A. (2010). Secondary School Students Misconceptions of Covalent Bonding. Turkey. Journal of Turkish Science Education. 7 (2), 3-29.

Zirbel, E, L. 2004. Framework for Conceptual Change. Tufts University, Department of Physics and Astronomy. 